\title{
DAVID HARVEY: LUGARES E ENCONTROS
}

JoÃo SARMENTO ${ }^{1}$

RESUMO - A importância da obra de David Harvey na história do pensamento geográfico e das ciências sociais é inestimável. Invariavelmente rotulado de Marxista ou mesmo pós-marxista, preocupado com a justiça espacial sobretudo no contexto urbano, o seu pensamento/trabalho dialético tem resultado em ideias e conceitos fundamentais para o desenvolvimento da Geografia e das Ciências Sociais e tem inspirado diversas gerações de académicos e intelectuais. O objetivo deste artigo é o de fornecer uma panorâmica sobre o trabalho deste geógrafo que cruzou diversos paradigmas na Geografia, identificando os momentos e lugares específicos das mudanças paradigmáticas, reconhecendo a importância de aspetos biográficos e das práticas sociais e institucionais nas práticas científicas e na produção intelectual. Esboça-se ainda a importância do seu legado científico através de uma análise preliminar da orientação de doutoramentos que Harvey conduziu nos últimos 45 anos.

Palavras-chave: David Harvey; ruturas epistemológicas; biografia; lugares; pensamento geográfico.

\begin{abstract}
David Harvey: Places and encounters. The importance of David Harvey's work in the History of Geographical Thought and of Social Sciences is invaluable. Invariably labelled as Marxist or even Post-Marxist, concerned with spatial justice especially in an urban context, his dialectical thinking/work has resulted in fundamental ideas and concepts for the development of Geography and the Social Sciences and has inspired several generations of intellectuals. The aim of this article is to present a panoramic view over the work of this geographer, identifying the very specific moments and places of paradigm change, recognising the importance of biographic details and social and institutional practices on scientific practices and intellectual production. An outline of the importance of his scientific legacy is also provided through a look at the doctoral supervision Harvey has conducted in the last 45 years.
\end{abstract}

Keywords: David Harvey; epistemological disruptions; biography; places; geographical thought.

1 Professor Auxiliar, Departamento de Geografia, Universidade do Minho \& Investigador Sénior, Centro de Estudos Geográficos, Universidade de Lisboa. Email: j.sarmento@geografia.uminho.pt 
RESUME - David Harvey : Lieux et Rencontres. L'ouvre de David Harvey a une importance inestimable dans l'histoire de la pensée géographique et des sciences sociales. Ayant toujours été considérée comme marxiste ou postmarxiste et soucieuse de justice spatiale dans un cadre urbain, sa pensée et son œuvre dialectiques ont donné lieu à des idées et à des concepts fondamentaux pour le développement de la Géographie et des Sciences sociales et ont inspiré plus d'une génération d'intellectuels. Cet article présente l'ensemble de l’œuvre d'un géographe qui a entrecroisé divers paradigmes, en identifiant les temps et lieux d'occurrence des modifications paradigmatiques; et qui a reconnu l'importance des aspects biographiques et des pratiques sociales et institutionnelles dans la recherche scientifique et la production intellectuelle. On suggère encore l'importance de son legs scientifique, par une analyse préliminaire des doctorats qu'il a dirigés au cours des 45 dernières années.

Mots clés: David Harvey; ruptures intellectuelles; biographie; lieux.

\section{INTRODUÇÃO}

The biographical details of how this book came to be written are relevant to reading it since they serve to explain features in its construction that might otherwise appear particular

(Harvey, 1973: 9)

A ciência - e naturalmente o conhecimento geográfico - está indelevelmente marcada pelo local e pelas circunstâncias espaciais que a produzem, pela corporalidade dos seus autores e objetos materiais, e pelos modos sociais e culturais de interação presentes (Shapin, 1998; Livingstone, 2003; Barnes, 2004, 2006). O percurso intelectual de David Harvey (1935-), o seu pensamento marxista dialético e as suas preocupações de justiça social, têm sido marcados pelos encontros com outros intelectuais e com outros lugares específicos em momentos particulares de tempo. Não defendo aqui que os lugares, com as suas idiossincrasias e contextos, têm determinado o percurso intelectual de Harvey, mas ainda assim são importantes no seu desenvolvimento.

O objetivo deste artigo é o de empreender uma viagem pelo trabalho de David Harvey, partindo de uma breve análise dos diferentes períodos e paradigmas pelos quais a sua obra foi passando, para depois evidenciar as ruturas e inflexões intelectuais e epistemológicas, que têm por base momentos, lugares e mudanças geográficas muito particulares da vida de Harvey. Ainda que não tendo tido, ou sendo conhecidas, experiências epifânicas à la Wittgenstein (Monk, 1990 in Barnes, 2006), o percurso e as práticas sociais de Harvey num determinado tempo e espaço constituem explicações importantes para as mudanças nas Geografias que construiu. Ainda que com isto não pretenda esboçar uma biografia de Harvey, não me posso alhear de alguns traços da sua vida. Tal como Barnes (2004: 570) afirmou, "Os cientistas não são órgãos sem face da racionalidade científica, mas pessoas reais com corpos, histórias, aptidões e interesses particulares que importam para o tipo de conhecimento produzido". 
Para elaborar esta construção recorri a diversas fontes, concentrando-me sobretudo nas mais extensas, publicadas em formato de livro (entre 1969 e 2014 Harvey publicou 21 livros com alguns cruzamentos entre si), dado que os artigos mais relevantes acabam por ser refletidos em livros de alguma forma mais tarde. Paradoxalmente, existem poucas análises panorâmicas da obra de Harvey. John Paterson publicou em 1984 o livro David Harvey's Geographies, resultado de uma revisão da sua dissertação de mestrado defendida em 1980, mas que aborda apenas os primeiros 20 anos da obra (1961-1981). John Paul Jones III publicou em 2004 a obra David Harvey (live theory), que por ser demasiado descritiva teve pouco acolhimento. Destacam-se Geographical Imaginations (1994) de Derek Gregory e, ainda que sem um carácter panorâmico mas com grande profundidade temática, a coleção de ensaios David Harvey. A critical reader (2006) editada por Noel Castree e Derek Gregory. Existe também uma escassez de artigos autobiográficos, e à exceção do capítulo 'Memories and Desires', publicado na obra editada por Peter Gould e Forest Pitts Geographical Voices: 14 Fourteen Autobiographical Essays, de 2002, republicado em parte em 2006 na coleção Approaches to Human Geography editada por Stuart Aitken e Gill Vallentine, a maioria das informações biográficas sobre Harvey está dispersa por prefácios, introduções ou breves notas nos seus livros.

\section{DIALÉTICAS DE HARVEY}

Sarmento (2008) analisou a obra de Harvey propondo quatro grandes blocos temporais entre 1965 e 2006, que não são de todo incompatíveis com as seis que aqui se sugerem para o período de 1955 a 2014. Apesar de não serem estanques e comportarem algumas sobreposições, tal como pode ser observado na figura 1, estas divisões representam momentos de tempo e de produção mais ou menos marcados e diferentes dos anteriores, ainda que possam manter uma continuidade paradigmática não compatível com as ruturas Kuhnianas. Sintomaticamente, os momentos de passagem de um para outro bloco, coincidem grosso modo com mudanças geográficas/físicas na vida de Harvey. A ciência regional (1955-1960), um período não contemplado por Sarmento (2008), representa o tempo em que Harvey realizava o doutoramento e analisava a transformação do uso do solo agrícola na sua região de Kent através de uma análise de dados históricos de arquivo e trabalho de campo exaustivo. Aspects of Agricultural and Rural Change in Kent, 1815-1900 (1962) é um estudo regional histórico que já não seguia a linha de análise de Richard Hartshorne, na qual os estudos se deveriam focar nas características de uma área em particular, mais do que nos processos que lhe estão subjacentes. A ciência espacial (1961-1968) refere-se a um período curto, de menos de uma década, no qual Harvey entra em contacto com as fundações de uma geografia dita cientifica. Abrange o período em que está a terminar o doutoramento (e tem uma experiencia marcante na Suécia e muda-se de Cambridge para Bristol) e culmina com a publicação de Explanation in Geography (EG), onde aplica metodologias das ciências naturais a problemáticas geográficas. Paradoxalmente, EG representa simultaneamente o ponto alto e o ponto final do desejo 

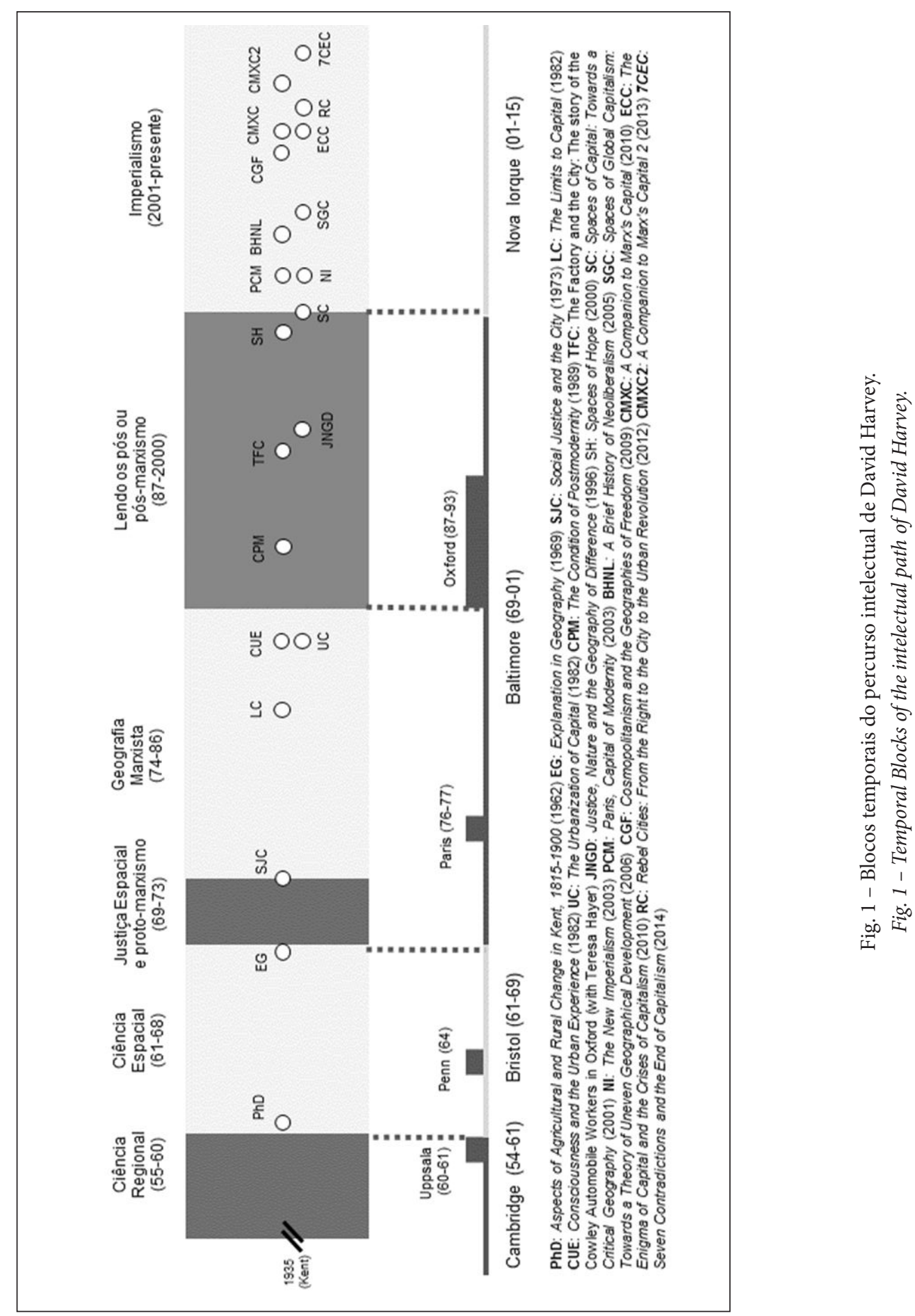
de Harvey contribuir para os princípios desta geografia científica (Castree, 2004). A justiça espacial e o proto-marxismo (1969-1973), um período que Sarmento (2008) não decompõe do período seguinte, diferencia-se desse sobretudo por ser uma fase de aproximação e aprendizagem do pensamento de Marx e da sua aplicação à Geografia. Inicia-se com o corte paradigmático da revolução quantitativa, seguramente mais radical do que os cortes analisados por Kuhn (1962), que defendeu que termos básicos como teoria, lei ou verificação, bem como formas de raciocínio científico, como seja a dedução lógica, reteriam o seu significado. Este corte, que coincide com a sua mudança de Bristol para Baltimore, destabiliza também a proposição kuhniana da 'má preparação' dos seguidores do antigo paradigma em abraçar novas ideias (Kuhn, 1962: 67). Harvey seguia assim por um novo trilho, criando uma 'teoria revolucionária', uma 'teoria validada através da prática revolucionária' (Harvey, 1972: 40). O período A Geografia marxista (1974-1986), corresponde à fase em que Harvey tenta estabelecer que as ideias da Geografia marxista são intelectualmente coerentes e mesmo empiricamente relevantes, e que tem o seu ponto alto em Limits to Capital (1982), uma obra plena de maturidade teórica. Mais uma vez, o período Lendo os pós- ou Pós-Marxismo (1987-2000) começa com uma mudança, na ocasião, de Baltimore para Oxford. Harvey tenta responder à transformação pós-moderna e pós-estruturalista na teoria social e nas artes, insistindo que o pós-modernismo não está livre das regras básicas do modo capitalista de produção. Nos círculos marxistas, Harvey passou a ser designado por pós-moderno, mas também como um teórico marxista pós-moderno (Harvey 2002; Barnes, 2006). O imperialismo (2000-presente) é um período que começa sensivelmente com a mudança de Baltimore para Nova Iorque, e que representa a análise das paisagens do capitalismo global e do imperialismo (sobretudo o Norte-americano), centrando-se no neo-liberal turn.

Ao invés de analisar cronologicamente cada um destes seis períodos - que poderiam até ser apenas três, caso delimitássemos unicamente as duas transformações paradigmáticas que ocorrem sensivelmente quando Harvey está a terminar o doutoramento, em 1960 e 1961, e mais tarde nos finais de 1968, mal termina o manuscrito de EG - optei por estabelecer cinco diálogos ou dialéticas do seu percurso intelectual, que permitem ver a emergência destes mesmos blocos cronológicos: Harvey meets Places, Harvey meets People, Harvey meets the world, Harvey meets the unexpected e People meet Harvey.

\section{Harvey meets Places}

Como muitos académicos contemporâneos, Harvey tem viajado bastante ao longo da sua longa carreira. Mas se nos centrarmos apenas nos lugares onde viveu mais tempo, chegamos à conclusão de que o geógrafo inglês é bastante conservador (geográfica, linguística e mesmo culturalmente). Nos primeiros 34 anos de vida, e referindo-me exclusivamente aos lugares onde viveu mais tempo, Harvey deslocou-se cerca de 120 quilómetros de Kent para Cambridge e menos de 300 quilómetros de Cambridge para Bristol. É certo que em 1969, quando se mudou de Bristol para Baltimore, passou por uma mudança maior, mantendo-se no entanto no mundo académico anglo-saxónico. Nos 
cerca de 45 anos seguintes deslocou-se apenas 300 quilómetros nos EUA, de Baltimore para Nova Iorque. Durante estes cerca de 80 anos, Harvey fez três estadias de um ano num país diferente daquele em que residia, dois dos quais não anglófonos e dois implicando travessias atlânticas: Uppsala em 1960-61, Pensilvânia em 1964 e Paris em 1976-77. Por uma vez realizou uma estadia mais prolongada de seis anos em Oxford (1987-1993), que foi quase um regresso a casa (quer a Kent, quer a Cambridge). De todos estes lugares, há sete que assumem uma importância especial. Baltimore e Paris servem para testar teorias e ideias, ou seja, são os laboratórios de Harvey, os truth spots como Barnes (2006) os classifica, ou lugares onde linguagens particulares de explicação e validação são aceites como 'verdade'. Um destes lugares, Baltimore, juntamente com outros dois, Cambridge e Bristol, estão implicados nas duas mudanças paradigmáticas principais. Kent, o seu condado natal, Nova Iorque, onde atualmente vive e a América Latina de um modo lato, assumem também importância. Passarei em seguida a detalhar este assunto.

\subsection{A Inglaterra até aos 35 anos: Kent, Cambridge e Bristol}

Harvey cresceu em Kent, numa paisagem rural, e é unicamente aqui que encontramos uma relação emotiva e sensual com a paisagem, o que é notável numa extensa obra dedicada aos processos de urbanização, e onde a estética está praticamente ausente. Ao contrário de muitos académicos interessados no urbano e em processos urbanos, não existe na obra de Harvey um encantamento com o visual e com as qualidades sensuais que fazem das cidades lugares diversos e reais. Para Harvey a contingência raramente assume um papel de destaque sendo que primeiramente as cidades foram construídas para a circulação de capital. Enquanto estudava em Kent, e mesmo já na Universidade em Cambridge, Harvey percorria Kent a pé e de bicicleta, interessando-se pela geologia, agricultura, mapas, e pelo declínio do império britânico. Esta decadência exterior tinha como efeito o favorecer 'vistas' para dentro do país. Em parte, e parafraseando Sidney Wooldridge, um professor de geomorfologia da Universidade de Londres nos anos 50 do século XX, “.... a atenção dos tolos está nos confins do mundo" (citado em Harvey, 2002: 155). Harvey, tal como muitos dos geógrafos na altura, consciente dos tumultos do mundo e do declínio do império, voltou-se para questões nacionais e locais, o que em parte encaixava na rivalidade existente entre a Royal Geographical Society, que continuou o seu apoio a explorações e exploradores pelo mundo fora, e o Institute of British Geographers, voz institucional dos geógrafos académicos, que por reação, se dedicaram a questões mais 'domésticas'.

Apesar deste olhar local e regional, enquanto estudava a transformação de uma paisagem rural e das plantações de lúpulo no sudoeste de Inglaterra, e analisava a evolução das notícias nos jornais no século XIX, Harvey apercebeu-se das ligações globais (comércio, tecnologia, política) que existiam entre a produção das plantações de açúcar nas Caraíbas e o consumo e sustento em Inglaterra. Num ensaio autobiográfico, Harvey descreve como as revoltas dos Mau-Mau no Quénia ou as contradições do império britânico 
no Sri Lanka ou no Chipre lhe provocaram marcas profundas (Harvey, 2002). Mas à exceção de um breve abandono dos estudos em Cambridge, resultado da sua indignação política pelo imperialismo materializado na Guerra do Suez em 1956, enquanto estudante Harvey raramente se envolveu em ativismos ou radicalismo estudantil. Esta maior reserva ou prudência contrasta com o ativismo apaixonado de algumas pessoas com quem anos mais tarde se cruzou, como sejam Manuel Castells (na sua juventude), e sobretudo Neil Smith. No seu cruzamento intelectual com Marx, encontrou também um ativista, particularmente na sua juventude.

No ambiente conservador de Cambridge onde Harvey estudou, há dois aspetos importantes a referir. Por um lado confrontou-se abertamente com algo que daí em diante o perseguiu: “...a opressiva realidade da diferença de classes e da segregação em Cambridge foi intensa e formativa" (Harvey, 2002: 162). Referindo-se repulsivamente a uma certa classe social como os 'aristocratas de Cambridge', Harvey alega que do seu círculo de amigos, nenhum tinha vindo de uma public school, isto é, de escolas pagas frequentadas quase exclusivamente pelas classes dominantes, por oposição às state schools. Por outro lado, nos anos 50 do século XX, o departamento de Geografia de Cambridge, a par com os de Washington (liderado por William Garrison, e o seu grupo space cadets que incluía William Bunge, Brian Berry ou Richard Morrill), Iowa e Lund, foi, especialmente com a chegada em 1958 de Richard Chorley e Peter Haggett, um dos lugares centrais da revolução quantitativa. Com o tempo estes centros reconfiguraram-se, continuando em Bristol (para onde Harvey foi em 1961 e Haggett em 1966), Chicago e Michigan. Quando Harvey se mudou de Cambridge para Bristol iniciou um diálogo forte com as geografias não só de Chorley e Haggett, mas também de Berry, Morrill, Edward Ullman e Michael Chisholm. Bristol era um dos centros do fervilhar da Geografia Quantitativa (Barnes, 2004) e Harvey, como geografo inglês formado em Cambridge, estava no olho do furacão.

Se é verdade que o seu trabalho de doutoramento e alguns artigos subsequentes não procurassem ainda propor uma teoria da transformação do uso do solo, Harvey foi tomando consciência desta importância, mostrando conhecimento e usando esparsamente teorias de localização como as de Weber ou Lösch. Em 1965, na Suécia, Harvey apresentou uma comunicação em que usou modelos de simulação de Monte Carlo, defendendo o desenvolvimento de modelos abstratos de aplicação generalizada, que pudessem ser usados para prever situações futuras. Nos anos subsequentes e até 1968, em Bristol, Harvey construiu aproximações entre modelos espaciais de pendor económico (Lösch, Isard, Garrison) e de pendor comportamental (Hägerstrand, Gould), participando no famoso livro editado por Chorley \& Haggett, em 1967, Models in Geography. Estes modelos foram mais tarde vertidos em EG.

\subsection{Baltimore nos anos 70}

Imediatamente após a publicação de EG, Harvey foi trabalhar para John Hopkins, Baltimore, para uma 'universidade privada de elite. Apesar de algo enigmática, esta 
mudança para um departamento cuja especialidade era a gestão de resíduos (Barnes, 2006), pode ter uma explicação mais pessoal, sendo que numa entrevista em 2014 com o escritor e ativista Paquistanês Tariq Ali, Harvey referiu o facto da sua mulher da altura, Barbara Koeppel, ser americana (Harvey, 2014). Tal como Bristol, Baltimore era uma cidade portuária, se bem que mais pobre e mergulhada num intensíssimo processo de declínio industrial desde a $2^{\text {a }}$ Guerra Mundial. No ano anterior à sua chegada tinham-se registado graves tumultos sociais relacionados sobretudo com o encerramento de empresas, e com forte desemprego. A estes problemas juntavam-se os movimentos contra a guerra no Vietname, pelos direitos civis e pela não discriminação racial. Harvey radicalizou-se e envolveu-se com a política local e com as lutas sociais existentes: "...compramos uma biblioteca antiga e transformámo-la num centro de ação comunitária, tomamos parte em campanhas para o controlo das rendas, e de um modo geral, procuramos inflamar iniciativas radicais" (Harvey, 2001: 16). Em 1969 o ambiente de tensão, de desigualdade social e racial era fortíssimo, mas no ambiente universitário conservador de J. Hopkins, as expedições e ligações de Harvey com a injustiça social da innercity não eram bem vistas. Apenas a sua tenure adquirida em 1972 - devido em grande parte à notoriedade e prestígio que EG lhe tinha trazido - evitou que não fosse obrigado a sair da instituição, seguindo o caminho de muitos que eram incómodos e tinham posições mais frágeis, como Donna Haraway por exemplo. Estes foram dias tumultuosos para Harvey, e a própria publicação de Social Justice and the City (SJ), um ano após a sua tenure, foi conturbada, sendo que vários avaliadores classificaram o livro como incoerente e ambíguo, recomendando mesmo a sua rejeição. Sem dúvida que estas práticas institucionais, algumas internas à disciplina, têm um papel crucial, frequentemente desvalorizado, nos caminhos intelectuais e académicos trilhados por diversos cientistas.

\subsection{A modernidade de Paris do século XIX}

Através de uma bolsa Guggenheim, Harvey esteve um ano em Paris (1976-1977), com a intenção de aprender com as discussões dos marxistas franceses: "encontrei-me e escutei-o [Manuel Castells] com grande interesse várias vezes em meados dos anos 70. Ele encorajou-me a vir para França" (Harvey, 2006: 188). Quando Castells reviu e traduziu La Question Urbaine (1972) para inglês (The Urban Question: a Marxist Approach, 1977), fez um agradecimento a Harvey pela ajuda, revisão e comentários de uma das suas partes novas, The case of the urban crisis in the United States, que Castells escreveu nos EUA, em 1975. Harvey tinha também algum contacto com a obra de Henri Lefebvre, se bem que a tenha usado muito parcimoniosamente em SJ: "os artigos neste volume foram completados antes de ter oportunidade de ler La Pensée Marxiste et la Ville (1972) e a Revolution Urbaine (1970) de Lefebvre" (Harvey, 1973: 302-303).

Talvez por Marx ter sido marcado de forma indelével pelos acontecimentos de Paris entre 1848 e 1851, Harvey debruçou-se também sobre como o capital e a modernidade se juntaram neste lugar e tempo específicos. Paris aparece nas duas obras de 1985 - The Urbanization of Capital: Studies in the History and Theory of Capitalist Urbanization (UC) 
e Consciousness and the Urban Experience (CUE) - em The Condition of Postmodernity de 1989, e em Paris, Capital of Modernity de 2003. Paris entre 1850 e 1870 serviu para Harvey encetar um diálogo ou dialética, entre as abstrações teóricas de LC e a geografia histórica da urbanização capitalista, entre as relações da teoria social com as condições de vida urbana e as dinâmicas das relações económicas e políticas entre o estado e a nação e o ambiente físico e cultural da cidade. Por outro lado, a destruição criativa ligada a Haussmann, os movimentos revolucionários e a luta da Comuna com os subsequentes massacres afloram em diversos momentos da análise de Harvey sobre o capitalismo atual.

\subsection{Nova Iorque e a América Latina}

Apesar de até aqui ter destacado estes cinco lugares (Kent, Cambridge, Bristol, Baltimore e Paris) como os mais significativos no percurso intelectual de Harvey, existem naturalmente outros que têm também alguma relevância, dos quais vou referir brevemente apenas mais dois. Desde logo Nova Iorque onde Harvey vive há cerca de 15 anos, sendo que a sua proximidade física e emocional a Wall Street não pode ser desprezada no contexto da sua obra pós-2001. Esta mudança foi o fechar de um círculo pessoal, desde o declínio do império britânico da juventude em Inglaterra até à ascensão de um império militar americano dos dias de hoje. Da mudança de John Hopkins para a City University of New York (CUNY), Harvey refere ainda que resultou de um ambiente demasiadamente sombrio na instituição de Baltimore, e que o veio revigorar, com o reencontro com Neil Smith e a aproximação a Cindy Katz. Por fim, o outro lugar que merece destaque é mais abrangente e diz respeito à América Latina, e cuja ligação remonta ao início dos anos 80 do século XX, altura em que Harvey visitou a Nicarágua e El Salvador, e publicou alguns textos sobre a emergência de sistemas económicos alternativos ao capitalismo. Juntamente com Barbara Koeppel, correspondente na revista americana de esquerda The Progressive, Harvey interessou-se pela génese da democracia participativa, pelos efeitos da violência militar, pela distorção feita pelos media norte americanos aos acontecimentos na América Latina, e pelo que designou de "efeitos devastadores do imperialismo Americano". Nas últimas décadas, também influenciado pelos laços familiares na Argentina (a sua mulher atual, Salmun Haydee, é Argentina, tendo completado em 1989 o doutoramento em John Hopkins, trabalhando tal como Harvey na CUNY), Harvey tem passado longos períodos na Argentina com a família, fortalecendo diversos laços no continente, tema que tocarei ainda no final deste artigo.

\section{Harvey meets People}

Apesar de se afigurar tarefa aliciante, não pretendo aqui discutir os encontros de Harvey com pensadores como Kant, Hegel, Marx, nem com escritores como Balzac ou Baudellaire. Quero antes focar a discussão nas influências e colaborações diretas que aconteceram sobretudo no início da sua carreira intelectual. Barnes (2004: 571) defende que a produção de ideias implica a criação e manutenção de networks and alliances. No 
percurso intelectual de Harvey é possível ver períodos claros de criação de redes e alianças nos momentos de criação de ideias e de construção de teorias, e de períodos mais individuais, quando as certezas são já mais firmes e as ideias mais consolidadas. Se tracei aqui a marca de três lugares que são responsáveis por uma mudança paradigmática (Cambridge e Bristol na primeira e Baltimore na segunda), várias são as pessoas que contribuíram diretamente para estas mudanças. Ainda que caindo no perigo que qualquer seletividade implica, destaco na primeira alteração da Regional Science para a Spatial Science, Richard Chorley em Cambridge e Gunnar Olsson em Uppsala. Em menor grau dois Peters, Haggett e Gould. Depois da Suécia, Harvey viu-se embrenhado com Olsson numa nova forma de fazer geografia. Diversas ideias do positivismo e das abordagens estatísticas de Chorley e Haggett foram incorporadas na sua dissertação. Ao mesmo tempo que Harvey estudava as plantações de lúpulo no século XIX em Kent, as questões de modernização, planeamento racional e método científico surgiam na geografia. "Eu precisava de mudar de engrenagem" disse Harvey (Harvey, 2002: 166). Em 1958, ainda enquanto doutorando de geografia histórica em Cambridge, Harvey foi monitor de uma disciplina de Richard Chorley e Peter Haggett. Ao preocupar-se mais com processos do que com características, usou o modelo gravítico e diversas regressões simples e análises de correlação, para estudar os padrões e o uso do solo (Barnes, 2006), Mais tarde, em 1970, admitiu que o uso destas técnicas foi meramente embelezador, estando a sua tese entre uma geografia regional tradicional e uma geografia da ciência espacial (Harvey, 1970 in Paterson, 1984: 24).

Na segunda mudança paradigmática, Harvey foi claramente influenciado pelo trabalho de William Bunge, que defendeu a ligação do trabalho teórico com o mergulhar no sofrimento da innercity, espelhado nas suas expedições geográficas em Detroit a partir de 1964. Encontraram-se por diversas vezes em Detroit nos anos 60, sobretudo no ano em que Harvey esteve na Penn State University com Peter Gould. Mais tarde, a partir de 1970, quando Harvey começou a ler Marx consistentemente, juntava-se com Bunge e Richard Peet (que por certo seguia uma linha mais anarquista), em torno dos avanços da revista Antipode. 'Wild' Bunge era o mais inflamado, o mais radical e criativo. Harvey, por seu lado, fazia e faz parte do grupo de geógrafos que se centraram na crítica teórica e filosófica marxista e não na ação prática. Mesmo 40 anos mais tarde, Harvey continua a justificar-se explicando que é a partir do lugar que ocupa na academia que a sua voz crítica se faz ouvir, tendo sempre uma relação tensa com a sua prática de intervenção, apesar de afirmar que muita da sua inspiração provém de movimentos sociais (Harvey, 2006: 187).

Em 1971 Harvey começou os cursos sobre o volume I de Das Kapital. O seu livro de 2010 A Companion to Marx's Capital baseia-se precisamente na transcrição das suas notas destes cursos, sendo que as respetivas gravações estão disponíveis online desde 2008, tendo registado dois milhões de downloads desde então. A regularidade e variedade dos cursos contribuíram marcadamente para que Limits to Capital (1982) seja considerado por Harvey o seu mais profundo livro teórico, "fornecendo uma casa teórica a partir da qual se explora o mundo" (Harvey 2002: 176). Ainda que não tenha alcançado a projeção que Harvey esperava e gostaria (LC foi republicado em 1999 e em 2006 tendo 
sido traduzido para português no Brasil passados 31 anos), é uma obra que recupera o espaço no Marxismo, defendendo a espacialização da dialética histórico-materialista, e ressaltando o movimento no espaço como central para o processo de acumulação de capital. Neil Smith, um dos primeiros doutorandos de Harvey, teve um papel fundamental neste processo de argumentação de que as ideias da Geografia marxista eram intelectualmente coerentes e mesmo empiricamente relevantes. O trabalho de Smith sobre o Desenvolvimento Desigual (1984), tem muito de Harvey. Precisamente no ano da publicação de LC (1982), Reagan e Thatcher assumiram o poder, o que assinalou um progressivo desvanecimento, quer na academia quer na sociedade em geral, do interesse na economia política marxista. Os desaires editoriais e académicos das obras de meados dos anos 80 do século XX (UC e CUE), juntamente com o desmoronar da vida pessoal aos 50 anos aproximaram-no da praxis política. Smith levou-o para inúmeros piquetes de protesto, e Harvey envolveu-se em ações de solidariedade. Apesar de todas estas cumplicidades, das 'redes e alianças' que marcam as mudanças paradigmáticas, é importante ressaltar que com a exceção de The Factory and the City: The Story of the Cowley Automobile Workers in Oxford, obra que publicou com Teresa Hayter em 1994, praticamente todos os livros de Harvey, são trabalhos individuais.

\section{Harvey meets the world}

Podemos identificar dois períodos em que a obra de Harvey está em claro contraciclo com os movimentos dominantes no mundo, e um mais recente em que se sintoniza em termos explicativos com o século XXI. O primeiro é bastante preciso, situando-se na conclusão do manuscrito de Explanation in Geography, que ironicamente aconteceu em agosto de 1968. Em 'contraciclo com o mundo', Harvey mergulhou no seu projeto quantitativo e procurou abstrair-se do que se passava à sua volta. Mais tarde argumentou que em parte "parecia absurdo escrever enquanto o mundo colapsava em caos à minha volta e cidades ardiam em chamas. Era como se Émile Zola estivesse zangado com os revolucionários na Comuna de Paris em 1871 porque estes atrasavam a publicação do seu primeiro romance" (Harvey, 2002: 168). O resultado deste 'atraso' na sua obra em relação ao que se passava no mundo foi Harvey ignorar EG após a sua publicação. O segundo contraciclo refere-se ao projeto ligado à geografia marxista. Por um lado, num primeiro momento, sensivelmente durante a década de 70 do século XX, o seu projeto estava alinhado com várias tendências na academia e mesmo na sociedade, mas tinha ainda uma forma teoricamente incipiente. Harvey avançou bastante até 1973, mas demorou oito anos até cristalizar uma série de artigos no livro Limits to Capital, em 1982. Num segundo momento, durante as décadas de 80 e 90 do século XX, após a sua maturidade teórica ter sido atingida com LC em 1982, a sua obra estava aparentemente desalinhada com o mundo, e o liberalismo dos anos 80 ditou que parecesse pouco relevante para geógrafos e não geógrafos.

Com a iminência da guerra do Iraque no início do século XXI, com manifestações a ocorrer em Londres e Nova Iorque, Harvey decidiu focar-se na condição global do capi- 
talismo e no papel que um novo imperialismo pode ter, e iniciou um novo ciclo na sua obra. Harvey tem defendido, seguindo de perto, entre outros, Rosa Luxemburg, que o processo de acumulação primitiva não cessou, e que as novas vagas de acumulação primitiva são fundamentais para a sobrevivência do capitalismo. Os exemplos são muitos: a abertura da China ao exterior e a criação de um proletariado urbano de baixos salários, a expulsão de camponeses na Índia para dar lugar a zonas económicas especiais, a extração violenta e continuada de recursos naturais em África, etc. Harvey argumentou que como pareceria um pouco estranho designar estes processos de acumulação primitiva, designou-os, nas suas obras The New Imperialism (2003) e A Brief History of Neoliberalism (2005), de acumulação por desapropriação. Assim, a teoria de uma forma capitalista de imperialismo é reformulada como uma fusão contraditória das políticas de estado e império com os 'processos moleculares' de acumulação capitalista no tempo e no espaço. O Pós-estruturalismo e o Feminismo que tinham sido levados em conta em Justice, Nature and the Geography of Difference (1996) e em Spaces of Hope (2000), sobretudo depois das fortes críticas que a CPM recebeu, esfumaram-se.

A crise financeira de 2008 veio convencer Harvey (se é que ele precisava de ser convencido) que Marx ainda era relevante. Harvey referiu que para perceber Marx há 40 anos atrás, era preciso compreender a teoria da sociedade civil de Gramsci, o imperialismo de Lenine e a legitimidade e racionalidade tecnológica da Escola de Frankfurt. Mas hoje em dia, no século XXI, Marx tornou-se óbvio, permitindo compreender processos de downsizing, a forma como as transformações tecnológicas destroem oportunidades de emprego, a forma como se tem produzido um 'exército industrial de reserva', etc.

\section{Havey meets the unexpected}

Lendo Latour (1987) percebemos que o inesperado, e mais especificamente alianças inesperadas, têm um papel crucial no progresso da ciência. Pessoas e objetos e lugares, que surgiram inesperadamente no percurso intelectual de Harvey marcam de sobremaneira a sua produção científica. A ida de Harvey para a Suécia em 1960-1961, para Uppsala e não Lund, enquadrado num pós-doutoramento (Leverhulme European Scholarship) surgiu a propósito de poder aceder a bases de dados demográficos mais precisas do século XVIII. Harvey terminou abraçando a Geografia Quantitativa e a estudar modelos espaciais na lógica hipotético-dedutiva. Tal como já referido, diversas ideias do positivismo de Auguste Comte e das abordagens estatísticas de Chorley e Haggett foram ainda incorporadas na sua dissertação (ver Harvey, 1963, que deriva em grande parte da sua tese). O encontro fortuito com Gunnar Olsson em Uppsala onde foram colegas de quarto "Quando cheguei a Uppsala em 1960, sem cerimónias fui deixado numa sala com um estranho de barba chamado Gunnar Olsson - um acontecimento que ambos naturalmente reconhecemos como um destes acidentes furtuitos que têm consequências duradouras" (Harvey, 2006: 186) - alterou radicalmente o curso da sua investigação e fê-lo aproximar do fervilhar quantitativo que aportava às ciências sociais. 
Tal como quando foi para a Suécia, Harvey fez em Baltimore algo completamente diferente do motivo pelo qual tinha sido contratado (reputado geógrafo autor de Explanation in Geography). Fez estudos detalhados sobre políticas urbanas, usando ideias de Engels para descrever as dinâmicas do mercado habitacional, e deu início a uma das suas persistentes batalhas: a ideia de que não há melhor enquadramento para compreender as dinâmicas do capitalismo no terreno do que as fornecidas por Marx e Engels. Ao mesmo tempo começou a interagir com professores e alunos da Universidade de Clark em Worcester, que a partir de 1969 começaram a publicar a revista Antipode (Barnes, 2004). Estas redes e alianças estabelecidas que surgiram inesperadamente, fruto dos lugares por onde passava e das pessoas que por aí encontrava, proporcionaram o abraçar de uma nova forma de pensar e fazer Geografia.

Aproveitando uma licença sabática em 1976-77, Harvey foi para Paris, mas desiludido com o que apelidou de arrogância de muitos dos intelectuais parisienses, incluindo os marxistas (como encaixaria um geógrafo anglo-saxónico neste mundo rarificado dos maitre penseurs, de Louis Althusser ou Nicos Poulantzas?), Harvey acabou por se interessar mais pela cidade de Paris, de Haussmann e de Napoleão. Mais uma vez, Harvey não fez o que tinha planeado, e esta experiência francesa fez com que Harvey convertesse a sua intenção de construir uma economia política urbana mais sólida numa tentativa de compreender toda a teoria marxista aplicada a questões históricas e geográficas. A teoria da economia política urbana pedia uma consideração séria do uso da terra como recurso, do capital financeiro, da formação de comunidade, do estado local, do investimento no ambiente construído, e sobretudo, da produção do espaço: "It took me almost a decade of hard slogging with a lot of help from students and even then it was not complete"(Harvey, 2002: 175).

\section{People meet Harvey}

A difusão de ideias e conhecimento é de difícil mensuração pois ocorre de formas distintas que atuam simultaneamente, e é afetada por muitos fatores distintos. Alguns deles são o número e qualidade de publicações, a sua receção e venda, a sua respetiva tradução para outras línguas, o número e qualidade das citações consequentes, o sucesso e abrangência de aulas, palestras e cursos, as visualizações de material online, as orientações de doutoramentos, etc. Para terminar estes diálogos, queria avançar com uma proposta que não pode deixar de estar incompleta, mas que penso ser importante para se estimar o legado de Harvey. À primeira vista, e contrariamente a Vidal de la Blache, Carl Sauer ou Orlando Ribeiro, Harvey parece não ter criado uma escola de geografia marxista com uma localização e contornos bem identificados. Das fontes disponíveis (catálogos das bibliotecas onde Harvey lecionou, do contacto com antigos orientandos e com o cruzamento de outras informações dispersas), foram identificados 34 doutoramentos concluídos orientados por Harvey (quadro I). Desde o primeiro em 1970 e o único defendido em Bristol, até 2014, Harvey participou na orientação de quatro doutoramentos em Oxford, sete na CUNY e os restantes 22 em J. Hopkins. Os temas destes trabalhos estão 


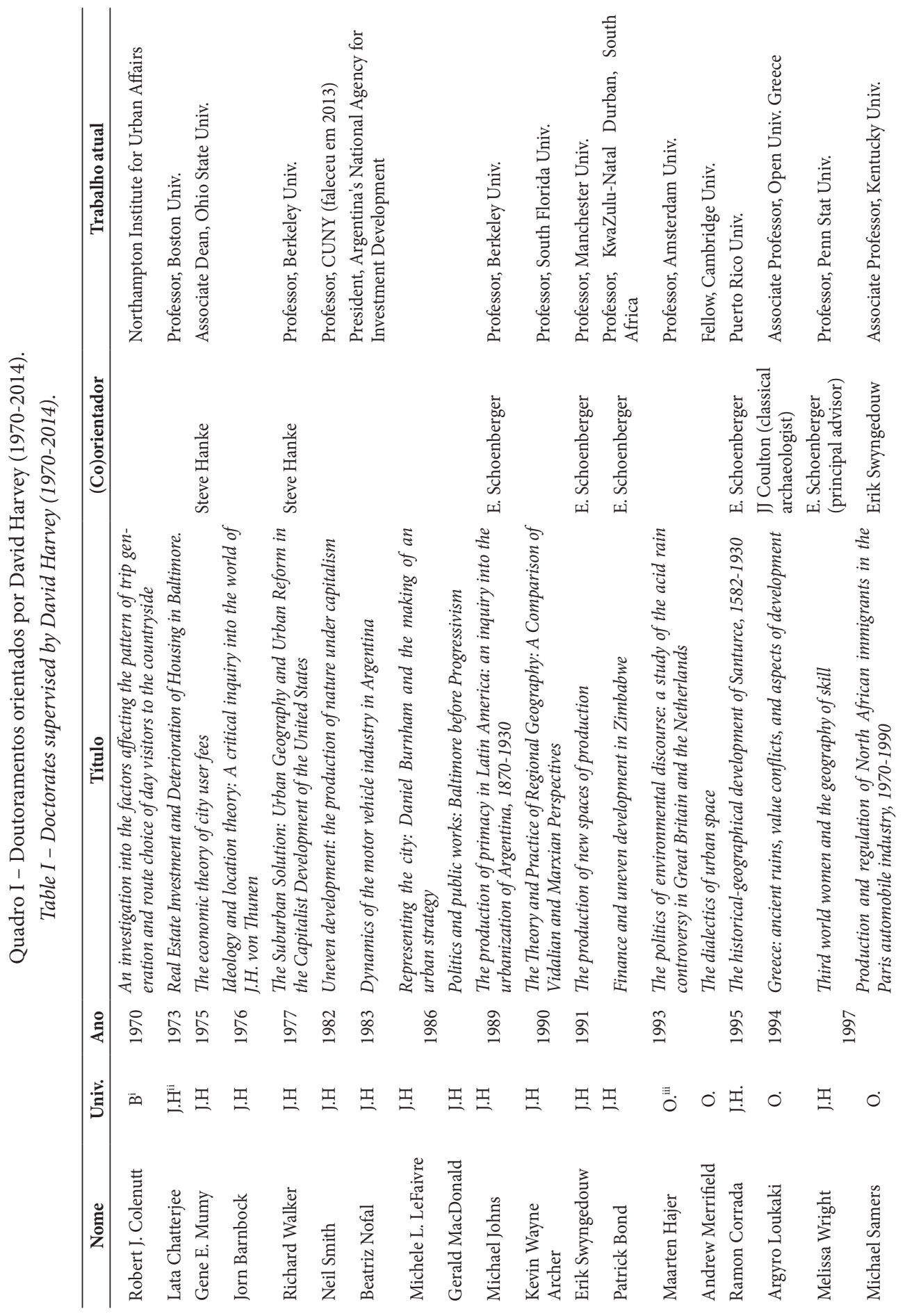




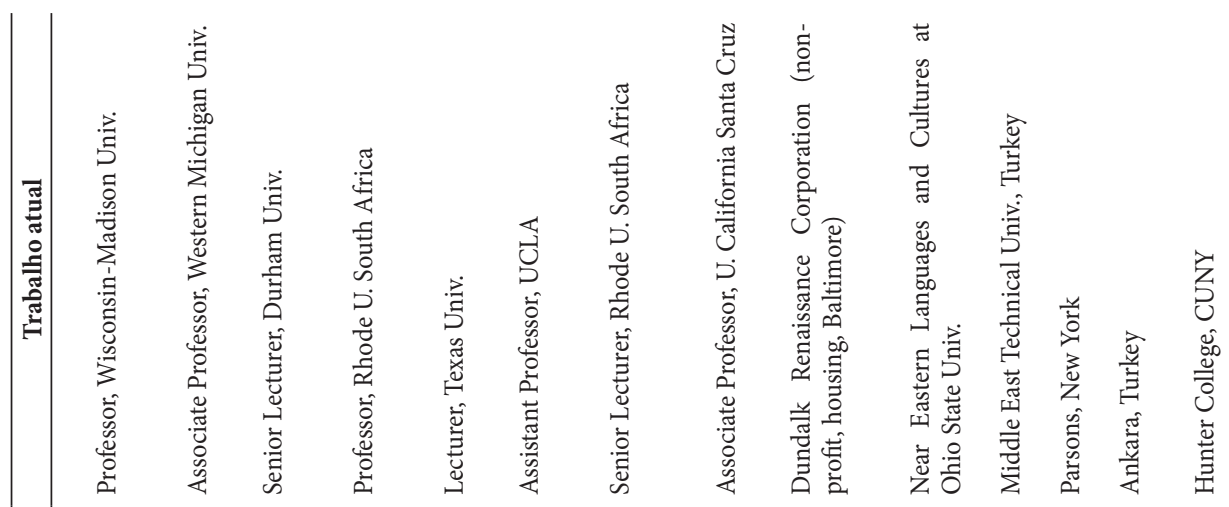
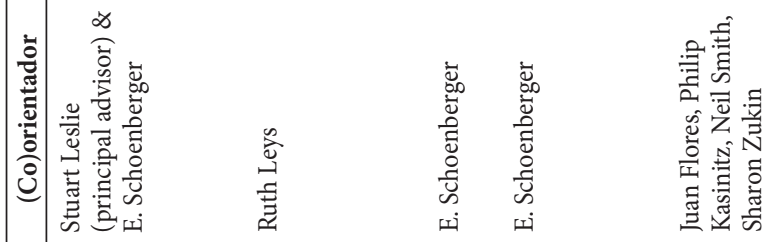

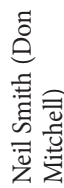

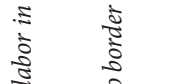

(1)

(1)

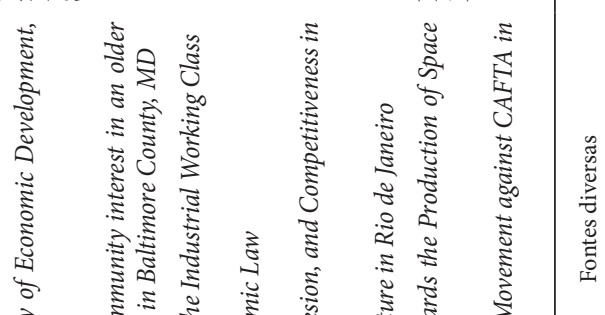

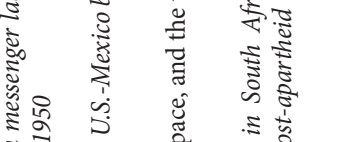

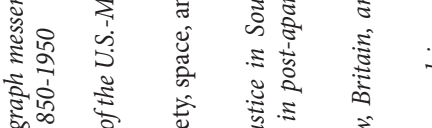

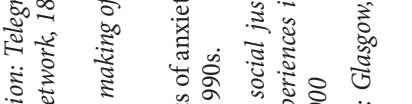

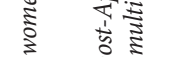

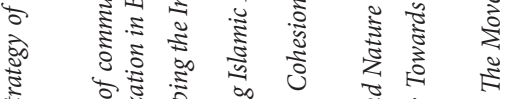

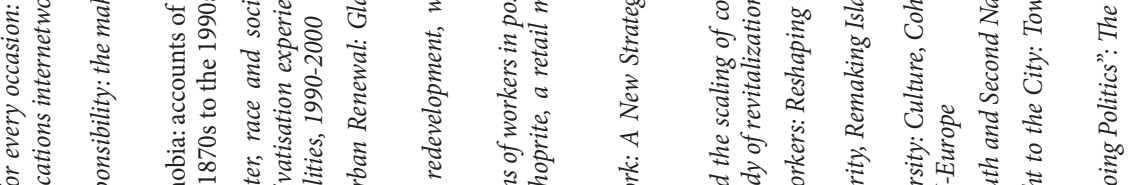

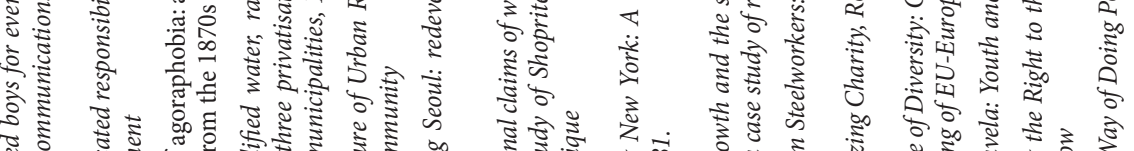

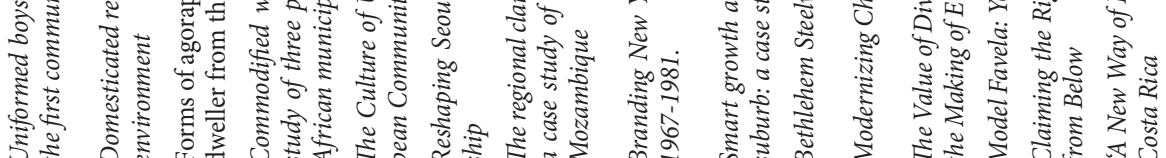
ई

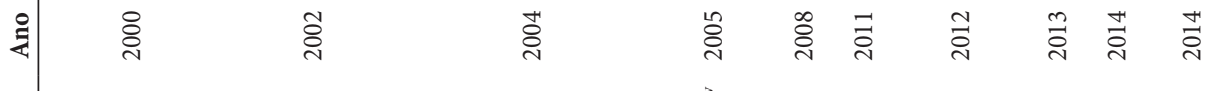

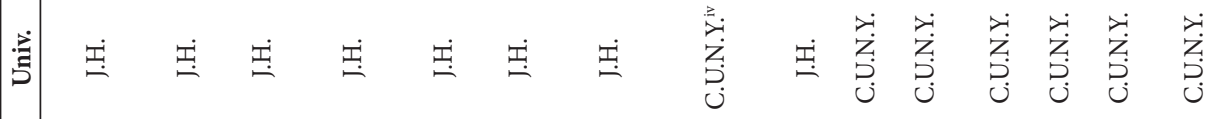

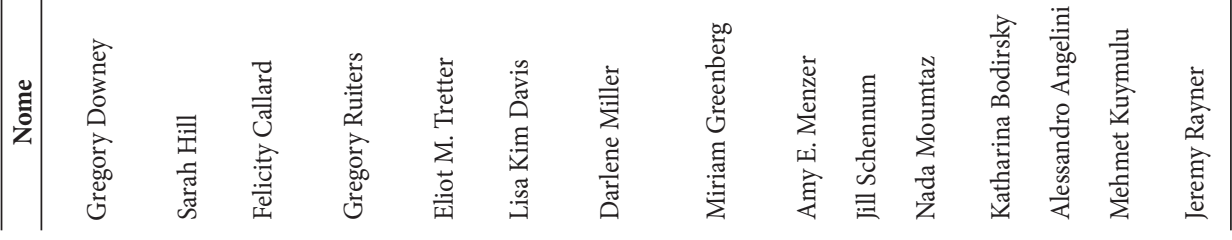


intimamente ligados com o capitalismo, o marxismo, o espaço e urbanização, e são reveladores e mostram uma consistência temática e teórica. Mais ainda, os lugares de trabalho destas 33 pessoas (Neil Smith faleceu em 2013), são na sua esmagadora maioria universidades, o que potencia uma continuação de produção científica, ainda que esta continuação aconteça sobretudo nos EUA, onde Harvey passou a maior parte da sua carreira. Ao mesmo tempo indica também a fraca ligação direta do desenvolvimento destas ideias em lugares que não a academia. Um olhar detalhado para esta primeira geração e futura ramificação da árvore é naturalmente importante e está por fazer, mas mesmo um relance breve para alguns destes académicos da primeira geração, e para as suas obras possibilita descortinar a eventual resiliência de diversas formas de marxismo na Geografia: Richard Walker (1977, Berkeley), professor Emérito, autor de Unholy Trinity. The IMF, World Bank and WTO (2003); Neil Smith (1982, CUNY), autor de Uneven Development: Nature, Capital and the Production of Space (1984) ou The New Urban Frontier: Gentrification and the Revanchist City (1996); Erik Swyngedouw (1991, Manchester), autor de Social Power and the Urbanization of Water - Flows of Power (2004); Andrew Merrifield (1993, Cambridge), autor de Metromarxism (2002). Entre académicos da segunda geração encontramos Michael Storper (1982, UCLA, orientado por R. Walker) ou Don Mitchell (1992, Rutgers, orientado por N. Smith). Ao mesmo tempo, ainda que frequentemente se critique Harvey por trabalhar a uma escala macro sem concretizar empírica e detalhadamente muitas ideias, a maioria dos trabalhos de doutoramento que orientou têm essa dimensão, e mais recentemente, vários focam-se em países do Sul Global: acordos de comércio na Costa Rica (2014), favelas no Rio de Janeiro, Brasil (2013) e Waqfs em Beirut, Líbano (2012).

Com 80 anos, Harvey viaja incansavelmente dando palestras e entrevistas, fazendo lançamentos de livros e participando em debates. Na cartografia destas suas viagens mais recentes, e excluindo os Estados Unidos, não é por acaso que vemos a Irlanda (Congresso dos Geógrafos Irlandeses), a Grécia (Departamento de Geografia em Atenas), mas sobretudo diversos locais da América Latina. Nos últimos anos, Harvey tem visitado numerosas cidades no Brasil, Argentina, Bolívia, Peru, etc., onde encontra uma recetividade extraordinária às suas obras. Demonstrando este interesse, as traduções das suas obras para espanhol e português são agora publicadas na América Latina pouco tempo depois da publicação dos originais em inglês. Será seguramente por aqui que as suas ideias, como por exemplo a de acumulação por desapropriação, mais continuidade irão ter. No mundo anglo-saxónico, onde tem deixado a maior parte dos seus discípulos formais, parece haver uma competição muito forte entre diversas teorias sedutoras - o mundo dos afetos, das emoções, da teoria não representacional, etc. - que revezadamente vão enchendo as grandes conferências, e tornando-se chave no acesso às revistas científicas com índices de impacto elevado. 


\section{CONCLUSÕES}

Ao longo deste texto foi possível ver que as mudanças paradigmáticas que parecem muito radicais, estão ligadas a contactos e contextos estabelecidos noutros espaços ou a mudanças pessoais de espaço ou lugar de trabalho (Uppsala em 1960-1961; de Cambridge para Bristol em 1961; de Bristol para Baltimore em 1969; em Paris em 1976-1977; em Oxford de 1987 a 1993; de regresso a Baltimore em 1993; a permanência em Nova Iorque desde 2001). Ao mesmo tempo, as realidades sociais destes novos espaços e as pessoas que Harvey aí encontrou foram fulcrais para o seu pensamento (a estratificação de classes em Cambridge; Haggett, Chorley e os quantitativos em Bristol; Olsson em Uppsala; os problemas sociais em Baltimore, o desencanto com os marxistas em Paris e o encanto pela cidade). Mais ainda, há uma série de acontecimentos sociais no mundo que não deixaram a sua obra indiferente: o declínio do império britânico e o seu modo de funcionamento; o Maio de 1968 e as lutas sociais dos anos 70 do século XX; o neoliberalismo dos anos 80 do século XX; a guerra do Iraque e a ascensão do imperialismo americano.

Mas ao mesmo tempo estas mudanças não são assim tão radicais. Certamente que existe um 'Harvey Mark I' e um 'Harvey Mark II' (Marx II como alguns dizem), mas ainda não há um Harvey Mark III. Harvey mantêm-se fiel a Marx, e em parte o seu grande sucesso atual, para além do seu rigor, seriedade, dedicação, prende-se com o facto dos seus textos lidarem com os problemas que afetam as pessoas em muitas partes do mundo, e com a sua resiliência em defender que a obra de Marx é muito útil para compreender o presente. Desde aproximadamente 1971 que Harvey tem andado a tentar mostrar duas coisas essenciais: a primeira é a que o processo de acumulação de capital, com tudo aquilo que implica em termos culturais, sociais e económicos, é uma questão profundamente geográfica. A segunda é que Marx continua a oferecer a melhor análise e crítica para compreender o modo de funcionamento capitalista, e por isso tem tentado torná-lo mais compreensível. A sua resiliência, isto é, a capacidade de retornar ao equilíbrio após stress e pressão, reside no facto de Harvey ter continuado a acreditar em Marx durante o final dos anos 70, durante os anos 80 e 90, alturas em que o colapso da União Soviética, o aparente sucesso das economias neoliberais, e a ascensão dos 'pós' na academia, provocaram um forte ataque ao marxismo. Hoje, no contexto da crise económica e financeira, as ideias e livros de Harvey encontram cada vez mais entusiastas dentro e fora da academia. O que este artigo aqui defendeu é que este percurso impar de criatividade intelectual não pode ser compreendido sem se olhar para as circunstâncias espaciais em que ocorreu e que também a produzem.

\section{AGRADECIMENTOS}

Agradeço a colaboração de Eliot Tretter, Erica Shoenberger, Miriam Greenberg, Richard Walker e Trevor Barnes na compilação da informação do quadro I. Agradeço a João Ferrão os comentários feitos na discussão da lição apresentada nas provas de agregação em Geografia Humana na Universidade de Lisboa em dezembro de 2014 com o título 'David Harvey, a evolução da ciência geográfica e a resiliência marxista'. Por fim, agradeço ainda as sugestões e comentários feitos pelos revisores científicos. 


\section{BIBLIOGRAFIA}

Barnes, T. J. (2004). Placing ideas: heterotopias, genius loci, and geography's quantitative revolution. Progress in Human Geography, 28 (5), 565-96.

Barnes, T. J. (2006). Between deduction and dialectics: David Harvey on Knowledge. In N. Castree \& D. Gregory (Eds.), David Harvey. A Critical Reader. Oxford: Blackwell.

Castree, N. (2004). David Harvey. In P. Hubbard, R. Kitchin \& G. Valentine (Eds.), Key thinkers on space and place (180-188). Londres: Sage.

Castree, N. (2006). The detour of critical theory. In N. Castree \& D. Gregory (Eds.), David Harvey. A Critical Reader (247-269). Oxford: Blackwell.

Castree, N. \& Gregory, D. (2006). David Harvey. A Critical Reader. Oxford: Blackwell.

Gregory, D. (1994). Geographical Imaginations. Oxford: Blackwell.

Harvey, D. (1963). Locational Change in the Kentish hop industry and the analysis of land use patterns. Transactions and Papers (Institute of British Geographers), 33, 123-144.

Harvey, D. (1969). Explanation in Geography. Londres: Edward Arnold.

Harvey, D. (1973). Social Justice and the City. Baltimore: John Hopkins University Press.

Harvey, D. (1979). Monument and Myth. Annals of the Association of American Geographers, 69 (3), 362-381.

Harvey, D. (1981). The spatial fix: Hegel, Von Thünen and Marx. Antipode, 13 (3), 1-12.

Harvey, D. (1982). The Limits to Capital. Chicago: University of Chicago Press.

Harvey, D. (1984). On the history and present condition of geography: an historical materialist manifesto. The Professional Geographer, 36, 1-11.

Harvey, D. (1985a). Consciousness and the Urban Experience. Oxford: Blackwell.

Harvey, D. (1985b). The Urban Experience. Oxford: Blackwell.

Harvey, D. (1989). The condition of postmodernity; an enquire into the origins of cultural change. Oxford: Blackwell.

Harvey, D. (1992). Postmodern morality Plays. Antipode, 24 (3), 300-326.
Harvey, D. (1996). Justice, nature and the geography of difference. Oxford: Blackwell.

Harvey, D. (1998). The Humboldt connection. Annals of the Association of American Geographers, 88, 723-730.

Harvey, D. (2000). Spaces of Hope. Edimburgo: Edinburgh University Press.

Harvey, D. (2001). Spaces of capital: towards a critical geography. Edimburgo: Edinburgh University Press.

Harvey, D. (2002). Memories and desires. In P. Gould \& F. Pitts (Eds.), Geographical voices: fourteen autobiographical records (149-188). Syracuse University Press, Siracusa.

Harvey, D. (2003a). Paris, Capital of Modernism. Londres, Routledge.

Harvey, D. (2003b). The new imperialism. Oxford: Oxford University Press.

Harvey, D. (2005). A brief history of neoliberalism. Oxford: Oxford University Press.

Harvey, D. (2006). Memories and desires. In S. Aitken \& Vallentine G. (Eds.) Approaches to Human Geography (184-190). Londres: Sage.

Harvey, D. (2010). A companion to Marx's Capital. Londres: Verso.

Harvey, D. (2004) Interview with Tariq Ali. 2 Setembro, http://www.davidharvey.org (acedido em Fevereiro 2015).

Latour, B. (1987). Science in action: how to follow engineers and scientists around society. Cambridge, Massachusetts: Harvard University Press.

Livingstone, D. N. (2003). Putting science in its place. Chicago: University of Chicago Press.

Paterson, J. L. (1984). David Harvey's Geography. Londres: Croom Helm.

Sarmento, J. (2008). David Harvey e a Geografia Cultural. In L. Correia L \& Rosendahl Z. (Eds.), Cultura: pluralidade temática (53-79). Rio de Janeiro: Editora EdUERJ.

Shapin, S. (1998). Placing the view from nowhere: historical and sociology problems in the location of science. Transactions of the Institute of British Geographers, 23, 1, 5-12.

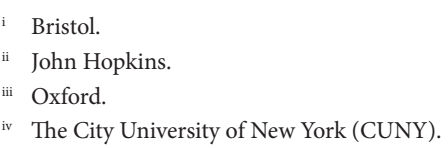

